Int. J. Morphol.,

36(1):130-134, 2018.

\title{
Attitudes of Undergraduate South African Students towards Body Donation
}

\author{
Actitudes de Estudiantes Sudafricanos de Pregrado hacia la Donación de Cuerpos
}

\author{
B. Z. De Gama ${ }^{1}$; T. T. Bhengu² \& K. S. Satyapal ${ }^{1}$
}

DE GAMA, B. Z.; BHENGU, T. T \& SATYAPAL, K. S. Attitudes of undergraduate South African students towards body donation. Int. J. Morphol., 36(1):130-134, 2018.

SUMMARY: A better understanding of students' attitudes towards body donation, their role as potential donors and their preparedness to support body donation activities may help in the preparation of body donor programme strategies. The aim of the study was to determine the willingness to self-donate, and the religious and cultural beliefs on body donation in a sample of South African undergraduate students. A cross-sectional study was conducted on Black African undergraduate students of two schools in their first to third years of study in a South African University between 2014 and 2015. Four hundred and twenty questionnaires were administered. A total of three hundred and seventy-two students completed the questionnaire. A low proportion of the respondents (14.7 \%) were willing to self-donate with the prevalent reason being to aid anatomical teaching. Religious beliefs were the predominant reason for unwillingness to self-donate. In addition, a low percentage of the students reflected that their religious (8.7\%) and cultural (4.1\%) beliefs permitted whole body donation. In conclusion, this study shares insights into the attitudes of undergraduate students towards body donation. For future body donation programmes, this group might not be a possible pool for such programmes. However, this group of students can assist in spreading the message to the public as they had very good knowledge about issues surrounding body donation.

KEY WORDS: Student; Body donation; Willingness; Religious; Cultural.

\section{INTRODUCTION}

The role of cadavers in anatomical and medical education, and also research, continues to be essential (Ajita \& Singh, 2007; Korf et al., 2008) amidst the introduction of new approaches and modes of teaching and learning in the last few decades (Alexander et al., 2014). In addition, cadaver dissection plays a vital role in the education of undergraduates around the world (Cahill \& Ettarh, 2008; Perry \& Ettarh, 2009; Saha et al., 2015; Ebeye et al., 2016). This practice of dissection has also been stated to not only favour the teaching of the foundations of anatomy, but also the development of professional competencies (Korf et al.). The practice of dissection has also been examined on whether it affects willingness to donate bodies among students i.e. future health professionals (Perry \& Ettarh; Anyanwu et al., 2014; Mwachaka et al., 2016). The cadaveric dissection room was proven to play an important role in the "shaping the students human emotional responses to death and dying" (Cahill \& Ettarh).
In recent times, it is difficult to talk about traditional dissection in an anatomy curriculum without managing a whole body donor programme which is dependent on a stream of body donations from the public (Perry \& Ettarh). This stream of body donations from the public is influenced by a variety of factors acquired from research in various parts of the world such as personal, psychological, educational, economic, cultural (Alexander et al.) and also religious (Mwachaka et al.). An enquiry into these factors has resulted in an increase of donated cadavers in some countries, while other countries still lack a steady stream (Biasutto et al., 2014). Therefore, it becomes important for each country to determine the factors and attitudes held by the public, in order to project the stream of cadavers required for the future of anatomical and medical education. Furthermore, the enrolees to body donor programmes from the public also include medical students whose attitudes are important for their future role in raising awareness about

\footnotetext{
${ }^{1}$ Clinical Anatomy, School of Laboratory Medicine and Medical Sciences, College of Health Sciences, University of KwaZulu-Natal, Westville Campus, Durban, South Africa

${ }^{2}$ Education, Development, Leadership, Management and Policy, School of Education, College of Humanities, University of KwaZulu-Natal, Edgewood Campus, Durban, South Africa
} 
donor programmes and also as potential donors (Perry \& Ettarh). In addition, it is imperative for educators to understand students' attitudes towards body donation as it may help adjust their approach to students on sensitive teaching and learning environments (Alexander et al.).

A review of the literature demonstrated at least six studies that investigated students attitudes towards body donation (Perry \& Ettarh; Alexander et al.; Saha et al.; Ebeye et al.; Mwachaka et al.; Abbasi Asl et al., 2017). The first study conducted in Ireland determined influence of age on the attitudes of medical students towards body donation (Perry \& Ettarh) while the second study conducted in Australia investigated attitudes of chiropractic students on whether cadaver-based anatomy instruction decreased support for body donation, in addition to investigating the influence of religion and ethnicity on support for body donation (Alexander et al.). The third study was based in India investigating the mentality and awareness towards body donation (Saha et al.). The fourth and fifth studies were based in the African continent (in Nigeria and Kenya, respectively) investigating attitudes of medical students and students in basic medical sciences towards body donation (Ebeye et al.; Mwachaka et al.). The sixth study was conducted in Iran focusing on the association between awareness about body donation, cultural acceptability and personal willingness to donate one's body after death (Abbasi Asl et al.). Interestingly, the findings of these studies varied.

The study by Perry \& Ettarh reflected one-third of the students supporting whole body self-donation while the study by (Alexander et al.) showed that religion and ethnicity play important roles in shaping students attitudes towards body donation. Saha et al. found willingness to body donate for the purposes of dissection to be poor amongst medical students. The studies by Mwachaka et al. and Ebeye et al. displayed low willingness to donate one's own body and a negative attitude towards corpse donation. The study by Abbasi Asl et al., showed significant association between awareness factors and personal willingness to donate while only "previous awareness of body donation centre or regulations" and cultural acceptability were found to not be associated with awareness factors.

In South Africa, bodies for both anatomical education and research are acquired through unclaimed bodies Kramer $\&$ Hutchinson (2015) and whole body donations (Riederer, 2016). Present and future health professionals and educators are stated to be generally expected to play a significant role in developing and maintaining body donation programmes (Alexander et al.). Furthermore, Alexander et al. elaborated that a better understanding of students' attitudes toward body donation, specifically, their role as potential donors and their preparedness to support body donation activities could assist in preparing donation programmes. Therefore, it becomes important to understand the held attitudes of the future Black South African students towards body donation as these to our knowledge have not been reported on yet.

Aim(s). The aim of the study was to investigate the willingness to become whole body donors and the religiouscultural attitudes of health science undergraduate students at a South African University towards whole-body donation in a multicultural context of South Africa.

\section{MATERIAL AND METHOD}

Study sample. A cross-sectional survey was conducted in 2014 and 2015 on first, second and third-year medicine, medical science, dental therapy, oral hygiene, occupational therapy, physiotherapy, pharmacy, optometry and communication pathology students undertaking the anatomy curriculum at a South African University.

Ethical considerations. Gatekeeper permission was obtained from the Deans and Heads of Schools of the two schools that the students belonged to. Ethics permission was obtained from the University of KwaZulu-Natal Biomedical Research Ethics Committee (BE 137/14).

Measures: There was one dependent variable and two independent variables in the study. The dependent variable was body donation (defined as an act of giving one's whole body after death for medical education and research), investigating the extent to which the students' were willing to self-donate. The first independent variable was religion (defined by Koenig (2009:284) as comprising beliefs, practices and rituals that are related to the sacred, to God, to the mystical or supernatural). The second independent variable was culture (defined as an internalized and shared framework that is used by a group of members as a refracted lens to "see" reality in which both individuals and the collective experience the world). The study investigated whether the two latter variables permitted for body donation.

Statistical Testing. Descriptive statistics (Pearson chi-square and Pearson correlation Test) were conducted using SPSS version 24 (IBM, Armonk, NY).

Study tool. A questionnaire was designed with guidance from previous literature to meet the objectives of the study. It had three sections with the first section requesting biographical information, the second section investigating knowledge and willingness to self-donate. The third and 
fourth sections investigated what the students understood as the opinion of their religious and cultural beliefs towards whole body donation. Students were surveyed in 2014 and 2015 during random semesters of those academic years.

\section{RESULTS}

A total of 420 students in their first, second and third years of study in two Schools at a South African University were surveyed during 2014 and 2015 academic years. The response rate for the questionnaire was $89 \%(372 / 420)$.

(a) Biographical data. According to sex, $66.8 \%(241 / 361)$ of the respondents were female, while $33.2 \%$ (120/361) were male. Students under the age of 21 years comprised $95.6 \%$ (346/362). The self-stated home languages (HL) were isiZulu $87.4 \%$ (325/372), isiXhosa $4.6 \%$ (17/372) and English 0.3 $\%$ (1/372). The remainder stated other languages in $7.3 \%$ (27/372). With regards to marital status, $99.7 \%$ (371/372) were single and $0.3 \%(1 / 372)$ were married. In relation to educational level, $94 \%$ (346/368) had completed secondary education while $5.4 \%(20 / 368)$ completed a tertiary qualification. For religion, $94.6 \%$ (351/371) subscribed to an organized religion while $2.1 \%(8 / 371)$ did not, the remainder subscribed to other religions $2.1 \%$ (8/371) and were undecided $1.1 \%$ (4/371). Those that subscribed to a religion included those who subscribed to Christianity in $87.6 \%(325 / 351)$ and African traditional religion (ATR) 7 $\%$ (26/351). Regarding employment status, $98.1 \%$ (365/ $372)$ were full-time students and $1.6 \%$ (6/372) were both students and part-time employed.

(b) Willingness to donate own body. A low percentage of $14.7 \%(53 / 361)$ stated willingness to donate their bodies to science while a higher percentage of $68.7 \%(248 / 361)$ was not. The reasons recorded for willingness to self-donate in 51 respondents were: to aid teaching of anatomy in 54.9 $\%(28 / 51)$ and to aid research in $21.6 \%$ (11/51). A statistically significant association and correlation between willingness to self-donate and reasons for willingness to self-donate was recorded $(\mathrm{X} 2=37.530, \mathrm{p}<0.001 ; \mathrm{r}=$ $0.306, p=0.023$ ). Reasons for lack of willingness to selfdonate were responded to by 246 respondents: $28 \%$ (69/ 246) stated religious beliefs, $22.8 \%$ (56/246) had "I do not want to" as a reason, cultural beliefs in $21.5 \%$ (53/ $246)$ and "fear of mutilation" $6.5 \%(16 / 246)$ by the students. The remainder of reasons were a combination of responses. No statistically significant association or correlation was found between willingness to self-donate and reasons for lack of willingness to self-donate $(\mathrm{X} 2=$ $15.334, \mathrm{p}=0.847 ; \mathrm{r}=0.057, \mathrm{p}=0.370$ ). (c) Religious attitudes towards BD. A total of $8.7 \%$ (32/ 368) stated their religion allowed for donation of bodies to science, while a higher percentage of $50 \%(184 / 368)$ recorded religion as not permitting $\mathrm{BD}$. The remainder of $41.3 \%(152 / 368)$ chose "Unsure" as a response. The reasons stated for religion permitting BD were "it is one of the good acts" in $48.4 \%$ (15/31) while $41.9 \%$ (13/31) stated a reason to aid teaching. With regard to reasons for religion not permitting BD, $40.7 \%$ (72/177) stated that the religious leader is against it while $37.9 \%(67 / 177)$ stated it is against the laws of their religion. Despite religious beliefs accounting for non-willingness to donate one's body, a weak positive statistically significant correlation between religion allowing for $\mathrm{BD}$ and reasons religion being against $\mathrm{BD}$ was obtained $(\mathrm{r}=0.190, \mathrm{p}=0.011)$. However, a statistically significant association was found between the two variables $(\mathrm{X} 2=7.029$, $\mathrm{p}=0.030)$.

(d) Cultural attitudes towards BD. A total percentage of $46.7 \%(172 / 368)$ believed in the existence and power of the ancestors, while $43.8 \%$ (161/368) did not. Of those believing in ancestors, a low $4.1 \%(7 / 172)$ stated ancestors would allow for BD while $80.8 \%$ (139/172) stated ancestors would not. The reasons stated for permitting BD were recorded as to enhance teaching in $33.3 \%$ (3/9) and research in $11.1 \%$ (1/ 9). The reasons for not permitting BD were: "it is against tradition" in $41.0 \%(94 / 229)$ while $36.7 \%$ (84/229) stated "it disturbs the spirit". However, no statistically significant association or correlation was found between ancestors allowing for body donation and reasons ancestors were against body donation $(\mathrm{X} 2=7.434, \mathrm{p}=0.491 ; \mathrm{r}=0.116, \mathrm{p}=0.078)$.

\section{DISCUSSION}

The socio-demographic representation of the sample in this study differed slightly from previous studies (Perry \& Ettarh; Alexander et al.; Ebeye et al.; Abbasi Asl et al.; Mwachaka et al.). With regards to sex distribution, this study had more female respondents than males. This distribution was similar to Ebeye et al. and Abbasi Asl et al., however, it differed from the studies of Perry \& Ettarh, Alexander et al. and Saha et al. A majority of the respondents in this study were under the age of 21 and this differed from studies of Perry \& Ettarh and Alexander et al., who had the majority of students above the age of 21 years. The majority home language in this study was isiZulu which reflected that these respondents belonged to the Zulu ethnic group of the Black African population group of South Africa. A majority belonged to an organized religion, with the prevalent religion being Christianity. This finding was similar to the study by Alexander et al. 
A small percentage (i.e. $14.7 \%$ ) demonstrated willingness to become whole body donors. The sample sizes and willingness to become whole body donors in previous studies of different student population groups varied from this study (Table I). This finding was concerning as the students in this study utilized cadaveric material during their studies either by cadaveric dissection or prosections. However, the findings in this study corroborated those of Anyanwu et al. who reported $13 \%$ of Nigerian students exposed to dissection room being willing to donate their body. The low levels of willingness to donate amongst the students in this study corroborated previous reports which also obtained low levels in self-donation for dissection (Perry \& Ettarh; Saha et al.; Ebeye et al.; Mwachaka et al.; Abbasi Asl et al.). A desire to aid the teaching of anatomy was the primary reason for willingness to donate their bodies in $54.9 \%$. This finding could not be compared with literature reviewed as this was not previously reported in a student population.

The primary reason for unwillingness to self-donate was religious beliefs. This finding differed from Anyanwu et al., Ebeye et al. and Mwachaka et al. who reported "family concern"; "I do not want my corpse to be disrespected" and cultural barriers as predominant reasons, respectively. Religious beliefs as a barrier to willingness to donate differed from percentages reported by the same authors. In this study, cultural beliefs were reported to be the reason for unwillingness to donate. This differed slightly from the reports by Ebeye et al. and Mwachaka et al.; however, the percentages varied in the different population groups. The comparison with these two previous reports in the African continent reflects that similar barriers or factors impact on willingness to donate in the different countries.

A very low percentage (i.e. $8.7 \%$ ) recorded that their organized religion permitted for body donation. A possible explanation to this could be similar to Ebeye et al. who stated that some believe that if any part of the body is donated or removed, the body would not be accepted by God and lineage continuity may be endangered. The primary reason stated for religion permitting body donation was that "it is one of the good acts" which confirms the theory that Christianity encourages any act of altruism (Slabbert et al., 2011). However, such an action is encouraged as long as it does not violate the dignity of the human person (Slabbert et al.). Half of the respondents reported that their religion was against body donation, this finding supported the notion that some people believe that donation conflicts with their faith (Ajita \& Singh).

With regard to religious beliefs not permitting body donation, the predominant reason was that "the leader is against it" followed by the "it is against the laws of their religion"; and a statistically significant association and weak relationship with these reasons was recorded. These findings reflect that, although major religions encourage donation, custodians of the religious laws such as religious leaders may not permit donation. In addition, the finding on the laws of the religion being highlighted as one of the reasons, reflects that the student respondents had a different understanding of the laws of their religion on body donation. This is congruent with Ajita \& Singh argument that people are often unaware of the attitude of their faith towards donation.

A low percentage of the respondents who believed in ancestors stated ancestors would allow for body donation. This agrees with findings of Ebeye et al. and Mwachaka et al. in a student population. The predominant reason for ancestors permitting body donation was to enhance teaching and this was similar to the student's reasons for being willing to selfdonate. Some students in the study by Mwachaka et al. reflected the human body as sacred and hence should be treated as such, while a few considered that their relatives would not find closure if they self-donated. The latter reason reflects the principle of Ubuntu which ensures a happy and qualitative community life in the spirit of family (Slabbert et al.). The reasons for ancestors not permitting body donation were that it "it is against tradition" and "it disturbs the spirit"; however, no statistically significant association or relationship was obtained. These views may be based on the culture of ancestral veneration that is prevalent amongst Black Africans (Adamo, 2011).

Table I. Comparison of willingness to self- donate with other different student population groups.

\begin{tabular}{lllll}
\hline \multicolumn{1}{c}{ Author (year) } & Country/City & Continent & \multicolumn{1}{c}{ Type of respondents } & $\begin{array}{c}\text { Levels of } \\
\text { willingness to } \\
\text { donate (sample size) }\end{array}$ \\
\hline Cahill \& Ettarh (2008) & Ireland & Europe & Medical students & $23.4 \%(212)$ \\
Perry \& Ettarh (2009) & Ireland & Europe & Medical students & $35.1 \%(40)$ \\
Anyanwu et al. $(2014)$ & Nigeria & Africa & Medical students & $13 \%(105)$ \\
Saha et al. $(2015)$ & India & Asia & Medical students & $6 \%(100)$ \\
Ebeye et al. (2016) & Nigeria & Africa & Basic medical science and medical students & $4.1 \%(707)$ \\
Mwachaka et al. $(2016)$ & Kenya, Nairobi & Africa & Medical students and surgical residents & $22.2 \%(72)$ \\
Abbasi Asl et al. $(2016)$ & Iran, Kashan & Asia & Medical Science & $25.4 \%(331)$ \\
De Gama et al. $(2016)$ & KwaZulu-Natal, & Africa & Medical science, medical and allied health & $14.7 \%(372)$ \\
& eThekwini & & students & \\
\hline
\end{tabular}


Limitations of this study were that it focused on Black African undergraduate students only. Recent studies have also incorporated postgraduate students and surgical residents. In addition, the sample size of this student population may not be a full representation of other undergraduate students in other provinces of the country. Further studies need to be conducted in the remaining eight provinces of the country to provide a complete and concise national representation.

CONCLUSION. Willingness to self-donate amongst this group who are exposed to cadaveric material is very low; this was primarily due to religious beliefs. This finding reflects that the predominant organized religion of Christianity in this group may not be supportive of body donation; thus agreeing with the thesis that religion plays an important role in shaping students attitudes towards body donation by Cahill \& Ettarh. Furthermore, religious beliefs were statistically proven to have a relationship with permitting body donation hence proving the hypothesis that religious beliefs may be a possible reason for low body donation rates among health science undergraduate students in a province of South Africa. However, cultural beliefs had no association or relationship with permitting body donation hence nullifying the hypothesis that cultural beliefs may be the reason for low body donor rates among this cohort of students.

This study has shed insights into the attitudes of undergraduate students towards body donation and has reflected that for future body donation programmes; this group might not be a possible pool of potential body donors. However, the same group of students can assist in spreading the message to the public as they had very good knowledge about body donation.

DE GAMA, B. Z.; BHENGU, T. T \& SATYAPAL, K. S. Actitudes de estudiantes sudafricanos de pregrado hacia la donación de cuerpos. Int. J. Morphol., 36(1):130-134, 2018.

RESUMEN: El propósito fue obtener un mayor conocimiento de las actitudes de estudiantes hacia la donación de cuerpo, su papel como potenciales donantes y su preparación para apoyar las actividades en la preparación de estrategias del programa de la donación. El objetivo del estudio fue determinar la voluntad de auto donar el cuerpo, además de las creencias religiosas y culturales sobre la donación de cuerpos en una muestra de estudiantes sudafricanos de pregrado. Se realizó un estudio transversal en estudiantes negros africanos de pregrado de dos escuelas, en su primer a tercer año de estudio en una universidad sudafricana entre los años 2014 y 2015. Se administraron 420 cuestionarios. Un total de 372 estudiantes completaron el cuestionario. Una baja proporción de los encuestados $(14,7 \%)$ estaban dispuestos a donar su cuerpo citando como razón predominante el apoyo a la enseñanza anatómica. Las creencias religiosas predominaron durante la encuesta ante la falta de voluntad de la auto-donación. Además, un porcentaje menor de los estudiantes reflejó que sus creencias religiosas $(8,7 \%)$ y culturales $(4,1 \%)$ permitían la donación de todo el cuerpo. En conclusión, este estudio entrega una mejor percepción de las actitudes de alumnos de pregrado hacia la donación de cuerpos. En el futuro, este grupo posiblemente podría no ser un buen referente para los programas de donación de órganos. Sin embargo, este grupo de estudiantes puede ayudar en la difusión de información al público, debido a que tenían muy buen conocimiento sobre los temas que se refieren a la donación del cuerpo.

PALABRAS CLAVE: Estudiante; Donación de cuerpos; Voluntad; Religioso; Cultural.

\section{REFERENCES}

Abbasi Asl, J.; Nikzad, H.; Taherian, A.; Atlasi, M. A.; Naderian, H.; Mousavi, G.; Kashani, M. M. \& Omidi, A. Cultural acceptability and personal willingness of Iranian students toward cadaveric donation. Anat. Sci. Educ., 10(2):120-6, 2017

Adamo, D. T. Christianity and the African traditional religion(s): The postcolonial round of engagement. Verbum Eccles., 32(1):1-10, 2011.

Ajita, R. \& Singh, Y. I. Body donation and its relevance in anatomy learning - A review. J. Anat. Soc. India, 56(1):44-7, 2007.

Alexander, M.; Marten, M.; Stewart, E.; Serafin, S. \& S`trkalj, G. Attitudes of Australian chiropractic students toward whole body donation: a crosssectional study. Anat. Sci. Educ.,7(2):117-23, 2014.

Anyanwu, E. G.; Obikili, E. N. \& Agu, A. U. The dissection room experience: A factor in the choice of organ and whole body donation--a Nigerian survey. Anat. Sci. Educ., 7(1):56-63, 2014.

Biasutto, S. N.; Sharma, N.; Weiglein, A. H.; Martínez-Beña, F.; McBride, J.; Bueno-López, J. L.; Kramer, B.; Blyth, P.; Barros, M. D.; Ashiru, O.; Ballesteros, L.E.; Moxham, B. J. \& Krishnan, S. Part I-Human bodies to teach anatomy: importance and procurement-experience with cadaver donation. Rev. Argent. Anat. Clin., 6(2):72-86, 2014.

Cahill, K. C. \& Ettarh, R. R. Student attitudes to whole body donation are influenced by dissection. Anat. Sci. Educ., 1(5):212-6, 2008.

Ebeye, A.; Ojebor, C. \& Ade, A. Perception to organ and corpse donation among students of basic medical sciences. Int. J. Forensic Med. Invest., 2(1):8-12, 2016.

Korf, H. W.; Wicht, H.; Snipes, R. L.; Timmermans, J. P.; Paulsen, F.; Rune, G. \& Baumgart-Vogt, E. The dissection course - necessary and indispensable for teaching anatomy to medical students. Ann. Anat., 190(1):1622, 2008.

Kramer, B. \& Hutchinson, E. F. Transformation of a cadaver population: Analysis of a South African cadaver program, 1921-2013. Anat. Sci. Educ., $8(5): 445-51,2015$

Mwachaka, P. M.; Mandela, P. \& Saidi, H. Repeated exposure to dissection does not influence students' attitudes towards human body donation for anatomy teaching. Anat. Res. Int., 2016: 9251049, 2016.

Perry, G. F. \& Ettarh, R. R. Age modulates attitudes to whole body donation among medical students. Anat. Sci. Educ., 2(4):167-72, 2009.

Riederer, B. M. Body donations today and tomorrow: What is best practice and why? Clin. Anat., 29(1):11-8, 2016.

Saha, A.; Sarkar, A. \& Mandal, S. Body donation after death: The mental setup of educated people. J. Clin. Diagn. Res., 9(6):AC05-9, 2015.

Slabbert, M.; Mnyongani, F. D. \& Goolam, N. Law, religion and organ transplants. Koers (Online), 76(2):261-82, 2011.

Corresponding author:

Prof. K.S. Satyapal

Clinical Anatomy

School of Laboratory Medicine and Medical Sciences

College of Health Sciences

University of KwaZulu-Natal

Private Bag X54001

Durban 4000 - SOUTH AFRICA

E-mail address: satyapalk@ukzn.ac.za

Received:19-01-2017

Accepted: 14-07-2017 